\title{
Meta-analysis of Prevalence of Depression, Anxiety and Stress Among University Students
}

\author{
Shifa Shaffique ${ }^{1, *}$, Sehar Shahzad Farooq², Haseeb Anwer ${ }^{1}$, Hafiz Muhammad Asif ${ }^{3}$, Muhammad Akram4, \\ Soon Ki Jung ${ }^{2}$ \\ 1Department of Physiology, Faculty of Life Sciences, Government College University Faisalabad, Pakistan \\ ${ }^{2}$ School of Computer Science and Engineering, Kyungpook National University, Daegu, Korea \\ ${ }^{3}$ University College of Conventional Medicine, Faculty of Pharmacy and Alternative Medicine, The Islamia University of Bahawalpur, \\ Pakistan \\ ${ }^{4}$ Department of Eastern Medicine, Government College University, Faisalabad, Pakistan
}

\section{ABSTRACT}

Background: The global burden on mental disorders have become too advanced with serious consequences on health and society. Over the years, depression, stress, and anxiety have become more common symptoms that affect all overpopulation pyramid irrespective of gender. Mental disorders are the second-most health indicator that causes morbidity.

Objectives: Mental disorders affect the entire population and both genders equally. Present study was conducted to carry out metaanalysis study to highlight the prevalence of anxiety, depression, and stress among university students.

Methodology: Various search engines i.e. Google scholar, Duckduckgo, AOL, Baidu, Yahoo as well as books and newsletter were used to collect the data.

Results: Despite tremendous development in the era of health and education, there is significant prevalence $(79.5 \%)$ of anxiety, depression, and stress in medical students that leads to morbidity and poor mental health disorders among these students.

Conclusion: It is concluded from meta-analysis study that prevalence of depression and anxiety is alarmingly high. There is a need of the hour to develop and design the mental health prevention programs and health education programs to overcome this issue.

\section{Keywords}

Anxiety, Community, Depression, Medical

Student, Stress.
*Address of Correspondence

shifa.shafiquee@gmail.com
Article info.

Received: July 23, 2020

Accepted: August 21, 2020

Cite this article: Shaffique S, Farooq SS, Anwer H, Asif HM, Akram M, Jung SK. Meta-analysis of Prevalence of Depression, Anxiety and Stress Among University Students. RADS J Biol Res Appl

Funding Source: $\mathrm{Nil}$

Conflict of Interest: Nil

Sci. 2020; 11(1):27-32.

This is an Open Access article distributed under the terms of the Creative Commons Attribution License (http://creativecommons.org/licenses/by/4.0), which permits unrestricted use, distribution, and reproduction in any medium provided the original work is properly cited.

\section{INTRODUCTION}

According to the World Health Organization (WHO), mental disorders are the leading cause of morbidity and it affects the quality of life. Studies regarding the emotional health of university students have revealed that depression symptoms are common among this population, and often are more than the general population for a reason that it is repository time of changing from adolescence to adulthood, thus, more prone to getting mental disorders ${ }^{1-3}$. Various prospective and retrospective studies suggested that university students are highly liable to developmental disorders ${ }^{4}$.

Stress is an unavoidable relationship between the person and their threatening environment while depression and anxiety are the response of an individual which relates to spectrum of mood disturbance ${ }^{5-7}$. Stress, depression, and anxiety are harmful for community and person as it can 
lead to the poor quality of life, effect on academic performance, negative behavior, and $4 \%$ chances of mental and physical ailments. Stress can be defined as the unavoidable relationship between a society and a person or an event of physical and emotional tension ${ }^{8,9}$. There are various emotional responses to stress i.e. feeling overwhelmed, agitation, sadness, and general unhappiness ${ }^{5,}{ }^{10}$. However, depression is a serious medical disorder that is persistent feeling of unhappiness and sadness. It varies from mild to severe ranges of symptoms and can lasts for longer time period without any apparent etiological factor ${ }^{11,12}$. Depression and other associate disorders affect the student's mental, physical and interpersonal functioning ${ }^{13}$, negative academic performance, causes clinical disorders like insomnia, anorexia nervosa etc. ${ }^{14,15}$. In a research on depression at university, students had been assessed for mental and neurological disorders that accounted for significant proportion of the total global liability ${ }^{16}$. Depression alone accounts for over $40 \%$ of the mental debilities. People with depression have a $40-60 \%$ chance of dying prematurely compared to the general population. It can cause many diseases like diabetes, myocardial infection, hypertension, and death due to suicides ${ }^{17-19}$. Furthermore, anxiety can be defined as a natural response to stress. It may be accompanied by a feeling of fear or apprehension. It is a normal reaction with altered physiological response i.e. raised blood pressure, alteration in cardiac activity and respiratory response 20-22. Therefore, the present study was designed to evaluate and compare the prevalence of depression, stress, and anxiety among university students.

\section{MATERIALS \& METHODS}

The comparative analysis was made by using various search engines i.e. Google scholar, Duckduckgo, AOL, Baidu, Yahoo as well as books, print media (newsletters) and news bulletin to collect the data to access the prevalence of depression, stress, and anxiety among university students.

\section{Data Collection Format}

To provide the most up to date information, the available epidemiological literature on prevalence of depression, stress, and anxiety have been collected since the beginning to the latest published data in 2020 including review papers, journal articles, conference publications and related blogs on the web.

\section{RESULTS}

\section{Comparative Studies}

A study was conducted during initial phase of COVID-19 to explore the psychological impact on college students of China. A total of $n=7,143$ students had participated in the study. Among all student's mental condition/illness, $75.1 \%$ showed normal mental status, followed by mild $(21.3 \%)$, moderate $(2.7 \%)$ and severe $(0.9 \%)^{23}$. Another webbased study was conducted in China to explore the level of stress and anxiety among students. The study was conducted on 1442 college students during first wave of pandemic and showed the raised level (26.63\%) of anxiety and depression among students. The COVID-19 is an event-related psychological phase. In this period, alarmingly high levels of mental health problems were reported ${ }^{24}$. Various studies during the phase of COVID-19 suggest the significant level of depression, stress and anxiety among students regarding their carrier, health, mental health, change in sleep pattern, use of social media, social disconnection and different attributes that causes negativity of thoughts and leads towards the regression ${ }^{25-27}$. The rate of depression in medical students is high because they face many difficulties during their medical curriculum ${ }^{28}$.

Another study conducted in Brazil showed that the prevalence of mental disorders among university students was $79.5 \%$, from which $40.5 \%$ were males ${ }^{29}$. The study suggested that mental health problems are more prone to be developed in males rather than females. The Franciscan University Counseling Center reports that the consulting requests to psychiatrists are higher almost after every mid-term session at university, which suggests that mental disorders are alarmingly raised due to numbers of reasons i.e. post-graduation plans, academic performance and pressure to succeed which become three top concerns for depression in graduate students. These factors are demographically identified in various students and also indicates that depressive symptoms in students may also be associated with academic impairment ${ }^{30,31}$. Many universities are running the mental health resources programs for betterment of students and eliminate depressive symptoms ${ }^{32,33}$. Different studies 
highlight that college students need more mental health services ${ }^{34-36}$. Since, depressive disorder is an illness that involves body, mood, and thoughts, therefore, continuous stress and depression directly affects the mental health of students. Anxiety takes several forms i.e. phobias, social anxiety, obsessive-compulsive, and post-traumatic stress disorders ${ }^{37-40}$. Quality of Life (QoL) and training efficiency of students affect due to professional challenges, demands and responsibilities directly or indirectly $41,42$. General stress, depression and anxiety symptoms are introduced with irrational beliefs ${ }^{43,44}$.

Furthermore, stress relating to professional and student lif $e$ is very important for learning, finding and attempting to force out of life ${ }^{45}$. A web-based longitudinal study was conducted in Japan to estimate correlation of stress with acculturative and connectedness among international and domestic students. They found a high rate of stress among international students (37.8\%) as compared to domestic students $(29.85 \%)^{46}$. Another study was conducted on 236 students enrolled in a nursing course to investigate the relationship between adverse childhood experience and post-traumatic stress. They revealed a higher level of stress in individuals who had adverse childhood experience ${ }^{47}$. A study was accompanied in the U.S during the election-2016 documented an eventrelated stress among students. The study revealed that one out of four students met the criteria of the eventrelated stress ${ }^{48}$. A China-based longitudinal study (1892) discussed the effect of stress, depression and anxiety in males and females. A total of 1888 students were taken from 15 different universities of equal gender. The study revealed that averagely both male and female were suffering from mild anxiety illness. The level of anxiety is more prevalent in females than males, while depression is more prone to be present in females ${ }^{49}$. Another study was conducted to correlate the adverse childhood experience with the prevalence of stress and showed a positive correlation of the adverse childhood experience with the level of stress. However, parents counselling and moral support among 321 individuals reported no mental illness ${ }^{50}$.

In a study, anxiety, and depression with the mental status of a person was correlated. These two indicators are mostly found in the students of the pharmaceutical and medical field. To observe depression and anxiety, two types of tests i.e. Beck anxiety inventory and Beck depression inventory are used ${ }^{51}$. The anxiety and stress are two major factors that drive students or individuals to take their live and commit suicide. Students with learning disabilities have higher rates of depression and anxiety ${ }^{52}$. Research work was published in China to notify the effect of uncertainty stress on mental disorders. This study consists of 11,594 individuals from 50 different universities. The Student Daily Stress Questionnaire (SDSQ) were used as a gold standard to find the correlation effect. They showed $22.8 \%$ mental disorders in medical students and positive correlation between the uncertainty stress and mental disorders ${ }^{53}$. Various other factors such as culture, values, environment and sex difference can also determine the level of depression and anxiety among students ${ }^{54,55}$. A study was conducted to find out the level of stress and depression in the crossculture model of Asian, Americans and European Americans. A total of 414 participants were taken to elucidate the effect of cross-culture. They observed a positive relationship between stress and depression with a cross-cultural model ${ }^{55}$.

Women are more likely to depress as compare to males at any stage of the life ${ }^{56}$. A study was conducted in 2002 at medical university Lahore, Pakistan which showed $43.7 \%$ and $19.5 \%$ of females to be reported for anxiety and depression, respectively. They concluded that females were more prone to mental illness than males ${ }^{57}$. Study evidence from the different universities in 37 countries suggested the emotional factors that may cause depression and stress. The unclear vision also leads to stress and anxiety. The students who come from other countries also face these problems. They get tension and anxiety as they live in very different societies, traditions, culture, and values.

They are having a tough time adapting to the new climate 58-60. Therefore, they usually go into depression easily. Sleep disturbances are also a specific and significant variable of depression. Moreover, the anxiety also leads towards depression in the first regression $30,61,62$. The medical field is highly significant in terms of a burden for the students. The medical students encounter increased depression and anxiety especially during their transition toward clinical settings. The relentless burden of anxiety and depression is taking them to the point of burn-out. 
Mental, social, and physical wellbeing have different dysfunctions, and psychosocial issues in students are often revealed because of anxiety ${ }^{63}$.

A study by Shams Uddin (2013) revealed that stress, depression, and anxiety are very common in students. Those are also linked to the difficulties of living professionally and academically. The working environment, performance pressure and culture of the academic institutes also affect the mental health of the students. The students belonging to the low socioeconomic background and financial vulnerability comparatively express depression, anxiety, and stress more ${ }^{64}$. The study also showed that depression or stress is less prevalent in students as compared to anxiety. Age is also contributing as an important factor with these three variables. However, there is need for further exploration to develop an appropriate support services and better intervention programs ${ }^{49}, 65$, keeping the fact in mind that university students are at high risk of anxiety and depression.

\section{CONCLUSION}

In the present study, cumulative, in-depth analysis of vast data from previously conducted researches validates that university students are at high risk of developing stress, anxiety, and depression. Among university students, medical students are more prone to become affected. It mainly affects academic performance, quality of life, serious health disorders and in several cases, lead to suicidal attempts. Certain measure such as primary and secondary health education programs and strategies to cope the certain unfavorable circumstances should be adopted to overcome and reduce the prevalence of depression, stress, and anxiety in overall population.

\section{ACKNOWLEDGEMENTS}

This research was supported by Basic Science Research Program through the National Research Foundation of Korea (NRF) funded by the Ministry of Education, Science and Technology (NRF-2019R1A2C1010786). This study was also supported by the BK21 Plus project (SW Human Resource Development Program for Supporting Smart Life) funded by the Ministry of Education, School of Computer Science and Engineering, Kyungpook National University, Korea (21A20131600005).

\section{LIST OF ABBREVIATION}

COVID-19 Corona Virus Disease

QoL Quality of Life

SDSQ

WHO Student Daily Stress Questionnaire World Health Organization

\section{REFERENCES}

1. Crow G. Social solidarities: Theories, identities and social change: Open University; 2002.

2. Ross SE, Niebling BC, Heckert TM. Sources of stress among college students. Social Psychol. 1999; 61(5):841-6.

3. Yakel E, Rieh S, St. Jean B, Markey K, Kim J. Institutional repositories and the institutional repository: College and university archives and special collections in an era of change. The American Archivist. 2008; 71(2):323-49.

4. Abouserie R. Sources and levels of stress in relation to locus of control and self esteem in university students. Educat Psychol. 1994; 14(3):323-30.

5. Horowitz MJ. Stress response syndromes. 1976.

6. Fazel M, Wheeler J, Danesh J. Prevalence of serious mental disorder in 7000 refugees resettled in western countries: A systematic review. The Lancet. 2005; 365(9467):1309-14.

7. Virtanen $\mathrm{M}$, Honkonen $\mathrm{T}$, Kivimäki $\mathrm{M}$, Ahola $\mathrm{K}$, Vahtera J, Aromaa A, et al. Work stress, mental health and antidepressant medication findings from the Health 2000 Study. J Affect Dis. 2007; 98(3):18997.

8. Greenberg J. Comprehensive stress management: McGraw-Hill Education; 2012.

9. Folkman S, Lazarus RS. Stress, appraisal, and coping: New York: Springer Publishing Company; 1984.

10. Pierceall EA, Keim MC. Stress and coping strategies among community college students. Comm Col J Res Pract. 2007; 31(9):703-12.

11. Beck DA, Koenig HG, Beck JS. Depression. Clin Geriatr Med. 1998; 14(4):765-86.

12. Blazer I, German D. Depression in late life: CV Mosby Co; 1993.

13. McKerrow I, Carney PA, Caretta-Weyer H, Furnari M, Miller Juve A. Trends in medical students' stress, physical, and emotional health throughout training. Med Edu Online. 2020; 25(1):1709278. 
14. Nestler EJ, Barrot M, DiLeone RJ, Eisch AJ, Gold SJ, Monteggia LM. Neurobiology of depression. Neuron. 2002; 34(1):13-25.

15. Bibring E. The mechanism of depression. 1953.

16. Organization WH. Depression and other common mental disorders: global health estimates. World Health Organization, 2017.

17. Othieno CJ, Okoth RO, Peltzer K, Pengpid S, Malla LO. Depression among university students in Kenya: Prevalence and sociodemographic correlates. J Affect Disord. 2014; 165:120-5.

18. Asante KO, Andoh-Arthur J. Prevalence and determinants of depressive symptoms among university students in Ghana. J Affect Disord. 2015; 171:161-6.

19. Beiter R, Nash R, McCrady M, Rhoades D, Linscomb $\mathrm{M}$, Clarahan $\mathrm{M}$, et al. The prevalence and correlates of depression, anxiety, and stress in a sample of college students. J Affect Disord. 2015; 173:90-6.

20. Spielberger CD. Anxiety and behavior: Academic Press; 2013.

21. Leary MR, Kowalski RM. Social anxiety: Guilford Press; 1997.

22. Beck AT, Emery G, Greenberg RL. Anxiety disorders and phobias: A cognitive perspective: Basic Books; 2005.

23. Cao W, Fang Z, Hou G, Han M, Xu X, Dong J, et al. The psychological impact of the COVID-19 epidemic on college students in China. Psychol Res. 2020; 287:112934.

24. Li Y, Wang Y, Jiang J, Valdimarsdóttir UA, Fall K, Fang $F$, et al. Psychological distress among health professional students during the COVID-19 outbreak. Psychol Med. 2020:1-3.

25. Rajkumar RP. COVID-19 and mental health: A review of the existing literature. Asian J Psych. 2020; 52:102066.

26. Livana P, Mubin MF, Basthomi Y. Learning task attributable to students stress during the pandemic Covid-19. J Psych Nursing. 2020; 3(2):203-8.

27. Peters MA, Wang $H$, Ogunniran MO, Huang $Y$, Green $\mathrm{B}$, Chunga JO, et al. China's internationalized higher education during Covid-19: collective student autoethnography. Postdigital Sci Edu. 2020: 1-8.

28. Hirsch JD, Nemlekar P, Phuong P, Hollenbach KA, Lee KC, Adler DS, et al. Patterns of stress, coping and health-related quality of life in doctor of pharmacy students. American J Pharm Edu. 2020; 84(3):1-7.
29. Baldassin S, Silva N, Alves TCdTF, Castaldelli-Maia JM, Bhugra D, Nogueira-Martins MCF, et al. Depression in medical students: Cluster symptoms and management. J Affect Disord. 2013; 150(1):1104.

30. Khesht-Masjedi MF, Shokrgozar S, Abdollahi E, Habibi B, Asghari T, Ofoghi RS, et al. The relationship between gender, age, anxiety, depression, and academic achievement among teenagers. J Family Med Pri Care. 2019; 8(3):799-805.

31. Alipio M. Predicting academic performance of college freshmen in the philippines using psychological variables and expectancy-value beliefs to outcomesbased education: A Path Anal. 2020; 1-15.

32. Duffy A, Saunders KE, Malhi GS, Patten S, Cipriani A, McNevin SH, et al. Mental health care for university students: A way forward? The Lancet Psy. 2019; 6(11):885-7.

33. Bibi A, Blackwell SE, Margraf J. Mental health, suicidal ideation, and experience of bullying among university students in Pakistan. J Health Psychol. 2019: 1-9.

34. Oswalt SB, Lederer AM, Chestnut-Steich K, Day C, Halbritter A, Ortiz D. Trends in college students' mental health diagnoses and utilization of services, 2009-2015. J American Col Health. 2020; 68(1):4151.

35. Bourdon JL, Liadis A, Tingle KM, Saunders TR. Trends in mental health service utilization among LGB+ college students. J American Col Health. 2020: 1-9.

36. North S. Addressing students' mental health needs via telehealth. North Carol Med J. 2020; 81(2):112-3.

37. Beloe P, Derakshan N. Adaptive working memory training can reduce anxiety and depression vulnerability in adolescents. Develop Sci. 2020; 23(4):e12831.

38. Russell G, Lightman $\mathrm{S}$. The human stress response. Nature Rev Endocrinol. 2019; 15(9):525-34.

39. Cool J, Zappetti D. The physiology of stress. Medical Student Well-Being: Springer; 2019. p.1-15.

40. Megson THG. Structural and stress analysis: Butterworth-Heinemann; 2019.

41. Watson D, Clark LA, Weber K, Assenheimer JS, Strauss ME, McCormick RA. Testing a tripartite model: II. Exploring the symptom structure of anxiety and depression in student, adult, and patient samples. J Abnorm Psychol. 1995; 104(1):15-23. 
42. Eller T, Aluoja A, Vasar V, Veldi M. Symptoms of anxiety and depression in Estonian medical students with sleep problems. Dep Anxi. 2006; 23(4):250-6.

43. Chang EC, D'Zurilla TJ. Irrational beliefs as predictors of anxiety and depression in a college population. Personal Ind Dif. 1996; 20(2):215-9.

44. Muran EM, Motta RW. Cognitive distortions and irrational beliefs in post-traumatic stress, anxiety, and depressive disorders. J Clin Psychol. 1993; 49(2):166-76.

45. Dudău DP, Sfeatcu IR, Funieru C, Dumitrache MA. Professional stress in relation to anxiety, depression and irrational beliefs among dental and psychotherapy students. Pro Soc Behav Sci. 2015; 187:158-62.

46. Nguyen MH, Le TT, Meirmanov S. Depression, acculturative stress, and social connectedness among international university students in Japan: A statistical investigation. Sustainability. 2019; 11(3):878-85.

47. Kalmakis KA, Chiodo LM, Kent N, Meyer JS. Adverse childhood experiences, post-traumatic stress disorder symptoms, and self-reported stress among traditional and nontraditional college students. J Amer Col Heal. 2020; 68(4):411-8.

48. Hagan MJ, Sladek MR, Luecken LJ, Doane LD. Event-related clinical distress in college students: Responses to the 2016 US Presidential election. J Amer Col Heal. 2020; 68(1):21-5.

49. Gao W, Ping S, Liu X. Gender differences in depression, anxiety, and stress among college students: a longitudinal study from China. J Affect Dis. 2020; 263:292-300.

50. Karatekin C, Ahluwalia R. Effects of adverse childhood experiences, stress, and social support on the health of college students. J Interpersonal Viol. 2020;35(1-2):150-72.

51. Ibrahim MB, Abdelreheem MH. Prevalence of anxiety and depression among medical and pharmaceutical students in Alexandria University. Alexand $\mathrm{J}$ Med. 2015; 51(2):167-73.

52. Bender WN, Rosenkrans CB, Crane M-K. Stress, depression, and suicide among students with learning disabilities: Assessing the risk. Learn Disab Quart. 1999; 22(2):143-56.

53. Wu D, Yu L, Yang T, Cottrell R, Peng S, Guo W, et al. The impacts of uncertainty stress on mental disorders of Chinese college students: Evidence from a nationwide study. Front Psychol. 2020; 11:243-9.

54. Hovey JD, Kim SE, Seligman LD. The influences of cultural values, ethnic identity, and language use on the mental health of Korean American college students. J Psychol. 2006; 140(5):499-511.

55. Mak WW, Law RW, Teng Y. Cultural model of vulnerability to distress: The role of self-construal and sociotropy on anxiety and depression among Asian Americans and European Americans. J Cross-Cult Psychol. 2011; 42(1):75-88.

56. Hopcroft RL, Bradley DB. The sex difference in depression across 29 countries. Soc For. 2007;85(4): 1483-507.

57. Rab F, Mamdou R, Nasir S. Rates of depression and anxiety among female medical students in Pakistan. EMHJ. 2008; 14(1):126-133.

58. Hunley HA. Students' functioning while studying abroad: The impact of psychological distress and Ioneliness. Int J Intercul Rel. 2010; 34(4):386-92.

59. Wielkiewicz RM, Turkowski LW. Reentry issues upon returning from study abroad programs. J Col Stud Develop. 2010; 51(6):649-64.

60. Savicki V. The effects of affect on study abroad students. Frontiers: Interdisciplinary J Study Abroad. 2013; 22:131-47.

61. Field $T$, Diego M, Hernandez-Reif M, Medina L, Delgado J, Hernandez A. Yoga and massage therapy reduce prenatal depression and prematurity. J Bodywork Mov Therap. 2012; 16(2):204-9.

62. Greenson RR. Phobia, anxiety, and depression. J Americ Psychoanal Associat. 1959; 7(4):663-74.

63. Ahmed I, Banu H, Al-Fageer R, Al-Suwaidi R. Cognitive emotions: depression and anxiety in medical students and staff. J Crit Care. 2009; 24(3):e1-e7.

64. Shamsuddin K, Fadzil F, Ismail WSW, Shah SA, Omar K, Muhammad NA, et al. Correlates of depression, anxiety and stress among Malaysian university students. Asian J Psych. 2013; 6(4):318-23.

65. Asif S, Muddassar A, Shahzad TZ, Raouf M, Pervaiz T. Frequency of depression, anxiety and stress among university students. Pak J Med Sci. 2020; 36(5): 4-12. 